\title{
O possível paralelismo entre a infecção da SARS-CoV-2 e tromboembolismo pulmonar: uma revisão integrativa
}

\author{
The possible parallelism between SARS-CoV-2 infection and pulmonary \\ thromboembolism: an integrative review
}

\section{El posible paralelismo entre la infección por SARS-CoV-2 y el tromboembolismo pulmonar: una revisión integradora}

Yan Santiago Nascimento ${ }^{1 *}$, Cecília Magalhães Porto Lira ${ }^{1}$, Ricardo Ferreira dos Santos Júnior ${ }^{1}$.

\begin{abstract}
RESUMO
Objetivo: Investigar o possível paralelismo entre a infecção da SARS-CoV-2 com eventos de Tromboembolismo Pulmonar (TEP), bem como seus mecanismos fisiopatológicos. Métodos: Trata-se de uma revisão integrativa nos idiomas português, inglês e espanhol, utilizando-se dos bancos de dados Google Acadêmico, SCIELO e PubMed, no período de dezembro de 2019 a fevereiro de 2021. Resultados: Em um grande estudo, incluindo 1099 pacientes positivos para SARS-CoV-2, descobriu-se que a concentração do marcador D-dímero foi observada acima de $0.5 \mathrm{mg} / \mathrm{lem} 46,4 \%$ dos pacientes, onde $60 \%$ deles desenvolveram manifestações graves. O grande risco de trombose foi demonstrado pelo aumento desse marcador, que se mostrou como uma das mudanças mais significativas na coagulação desses pacientes. Um estudo utilizando do software de estatísticas SPSS dem onstrou que a prevalência de embolia pulmonar em pacientes com SARS-CoV-2 é maior do que naqueles em que não se estabeleceu a doença ( $26 \%$ vs. $16 \%)$, confirmando dados publicados em outros estudos e alarmando ainda mais a necessidade de estudar essa relação. Considerações finais: $A$ incidência do TEP em pacientes acometidos com SARS-CoV-2, está sendo constantemente relatada na bibliografia, demonstrando a relevância da possível associação. Estudos mais aprofundados a respeito desse possível paralelismo são cada vez mais necessários.
\end{abstract}

Palavras-chave: Embolia pulmonar, Infecções por coronavírus, Embolia, Trombose, Anticoagulantes.

\begin{abstract}
Objective: To investigate the possible parallelism between SARS-CoV-2 infection and Pulmonary Thromboembolism (PE) events, as well as their pathophysiological mechanisms. Methods: This is an integrative review in Portuguese, English and Spanish, using the Google Academic, SCIELO and PubMed databases, from December 2019 to February 2021. Results: In a large study, including 1099 SARS-CoV-2 positive patients, it was shown that D-dimer concentration was above $0.5 \mathrm{mg} / \mathrm{I}$ in $46.4 \%$ of patients, in which $60 \%$ developed severe manifestations. The high risk of thrombosis was increased by the rise in this marker, which was proven to be one of the most relevant changes in coagulation in these patients. A study using the SPSS statistics software showed that the prevalence of pulmon ary embolism in patients with SARS-CoV-2 is higher than in those without the disease (26\% vs. $16 \%)$, confirming data published in other studies and further highlighting the need to study this relationship. Final considerations: The incidence of PTE in patients affected with SARS-CoV-2 is constantly being reported in the bibliography, demonstrating the possible association. Further studies regarding this possible parallelism are increasingly defined.
\end{abstract}

Key words: Pulmonary embolism, Coronavirus infections, Embolism, Thrombosis, Anticoagulants.

\section{RESUMEN}

Objetivo: Investigar el posible paralelismo entre una infección por SARS-CoV-2 y eventos de Tromboembolismo Pulmonar (EP), así como sus mecanismos fisiopatológicos. Métodos: Esta es una revisión integradora en portugués, inglés y español, utilizando las bases de datos Google Academic, SCIELO y PubMed, de diciembre de 2019 a febrero de 2021. Resultados: En un estudio grande, que incluyó 1099 pacientes positivos para SARS-CoV-2, es encontraron que la concentración del marcador D-dímero se observó por encima de 0,5 mg / I en el 46,4\% de los pacientes, donde el $60 \%$ de ellos desarrolló manifestaciones graves. El alto riesgo de trombosis se sumó al aumento de este marcador, que resultó ser uno de los cambios de coagulación más relevantes en estos pacientes. Un estudio que utilizó el software estadístico SPSS mostró que la prevalencia de embolia pulmonar en pacientes con SARS-CoV-2 es más alta que en aquellos sin la enfermedad (26\% frente a $16 \%$ ), lo que confirma los datos publicados en otros estudios y alarma aún más la necesidad para estudiar esta relación. Consideraciones finales: La incidencia de TEP en pacientes afectados de SARS-CoV-2 se informa constantemente en la bibliografía, lo que demuestra una asociación de la posible asociación. Cada vez se definen más estudios sobre este posible paralelismo.

Palabras clave: Embolia pulmonar, Infecciones por coronavirus, Embolia, Trombosis, Anticoagulantes.

1 Universidade de Pernambuco (UPE), Recife - PE. *E-mail:yan.nascimento@upe.br 


\section{INTRODUÇÃO}

A nova infecção por coronavírus é causada pela Síndrome Respiratória Aguda Grave 2 (SARS-CoV-2) e foi detectada pela primeira vez em 31 de dezembro de 2019 na cidade de Wuhan, na China, possuindo um mecanismo fisiopatológico que envolve uma exagerada resposta inflamatória que pode levar a manifestações graves, como síndrome respiratória do adulto, sepse, coagulopatiae, até mesmo, morte (FRANCO-MORENO A, et al., 2020). Os coronavírus consistem em uma grande família de vírus de RNA de cadeia e foram identificados décadas atrás, entretanto não tiveram significância clínica e potencial epidêmico reconhecidos até o surto da SARS-CoV e Síndrome Respiratória do Oriente Médio (MERS) em 2002 e 2012, respectivamente (MIESBACH W e MAKRIS M, 2020).

A SARS-CoV-2 apresenta, além de uma mortalidade expressiva, um aumento exponencial no número de pacientes infectados e uma quantidade muito alta de pacientes em hospitais, causando assim, um colapso não só na rede de saúde, como na economia dos países ao redor do globo. A SARS-CoV-2 é o sétimo membro do CoV a ser identificado e é semelhante estruturalmente ao SARS-CoV, compartilhando cerca de $72 \%$ de seu genoma (LIMA FLO, et al., 2020)

Seu diagnóstico é microbiológico e feito rotineiramente porRT-PCR (reação em cadeia da polimerase com transcriptase reversa), geralmente em amostras de nasofaringe ou seções respiratórias. Testes de imagem, como a Tomografia Computadorizada (TC) de tórax, por exemplo, tem uma grande sensibilidade e permite avaliar o envolvimento pulmonar e suas complicações, além de fornecer diagnósticos alternativos (CHAMORRO EM, et al., 2021). A radiografia de tórax é o exame de mais fácil acesso na grande maioria dos hospitais e clínicas, entretanto apresenta uma sensibilidade reduzida, principalmente quando utilizada para identificação de manifestações prévias, não sendo indicada para exclusão diagnóstica (LIMA FLO, et al., 2020).

Nesse sentido, a SARS-CoV-2 vem se provando, por diversas vezes, desafiado ra de se lidar. Isso porque, além de sua rápida transmissão, tem grande reatividade com a Angiotensin Conversor Enzyme (ACE 2), enzima presente em diversos órgãos, podendo af etar desde o pulmão, intestino e coração, até mesmo órgãos menores como a tireoide, determinando a dificuldade de controle da doença (COSTA IBSS, et al., 2020). Após a ligação ao seu receptor, ACE2 ativa o sistema renina-angiotensina, que leva a uma regulação negativa da expressão dessa enzima, resultando em um aumento na angiotensina II e uma diminuição na angiotensina (MIESBACH W e MAKRIS M, 2020).

Enquanto a maioria dos pacientes apresentam apenas sintomas leves, uma característica dessa infecção é que uma proporção de pacientes desenvolve complicações graves dentro de um curto período de tempo, como Síndrome Respiratória do Adulto (SDRA) e a Coagulação Intravascular Disseminada (CIVD) devido a uma possível tempestade de citocinas e tromboembolismo pulmonar. As coagulopatias, devido a inflamação, hipoxia, dano endotelial e coagulação intravascular difusa, são uma anormalidade relativamente comum em pacientes da SARS-CoV-2 (FAJGENBAUM DC e JUNE CH, 2020).

Diversos estudos de imagem e laboratoriais relataram um risco aumentado de complicações trombóticas em pacientes com a infecção por SARS-COV-2. Em um desses estudos, utilizando-se de estatísticas do software SPSS (IBM, Inc), foi exposto que a prevalência de embolismo pulmonar em pessoas acometidas pela doença é maior do que aqueles em que a doença ainda não se estabeleceu (26\% vs. $16 \%$ ) (CHAMORRO EM, et al., 2021). Dessa maneira, o objetivo desse estudo teve por finalidade analisar a correlação entre as complicações trombóticas e a SARS-CoV-2 sendo revisados estudos anteriores que relatam essa convergência em pacientes ating idos pela infecção, bem como estudos embasados em dados desse sof tware, buscando fazer uma revisão integrativa abrangente e atual.

\section{MÉTODOS}

Foi realizada uma revisão de literatura integrativa, utilizando como período de corte entre dezembro de 2019 a fevereiro de 2021. Foram utilizados os idiomas português, inglês e espanhol, abrangendo um total de 37 artigos. Os estudos foram pesquisados e revisados no banco de dados do Brasil Scientific Electronic Library Online (SCIELO) e PubMed, via Sistema Online de Busca e Análise de Literatura Médica (MedLine), utilizando a lista de referência dos artigos para expansão da pesquisa e consultando profissionais da área de saúde. 
Foram utilizados como descritores para a pesquisa na base de dados: "Embolia Pulmonar", "Infecções por Coronavírus", "Embolia e Trombose", "Trombose" e "Anticoagulantes", de acordo com o DeCS.

Como método de inclusão, foram utilizados os trabalhos originais recentes que já possuíam aprovação pela comunidade científica e estavam acoplados às bases de dado descritas. Foram revisadas metanálises, artigos de revisão, estudos observacionais e guias clínicas referentes à pacientes adultos hospitalizados por SARS-CoV-2. Foi utilizado como método de exclusão trabalhos que se distanciaram da temática a partir da leitura, os que possuíam pequeno tamanho amostral e os que avaliaram a população pediátrica.

A imagem utilizada para a representação da metodologia foi feita utilizando o website do Canvas, almejando uma facilidade na interpretação do leitor e uma suavidade na visualização das informações contidas dentro do método.

A avaliação de elegibilidade dos artigos foi feita de forma independente pelos três revisores. As discordâncias entre os revisores foram resolvidas em consenso.

De acordo com a Figura 1, foram selecionados inicialmente 209 artigos pelo MedLine e Scielo, somados a 75 de outras fontes. Foram excluídos estudos duplicados sobrando 216. Após isso foram utilizados como métodos de exclusão os artigos pediátricos, de pequeno tamanho amostral e com população fora de interesse, subtraindo 110 artigos. Com os 106 restantes, foram retirados 69 que possuíam população foram de interesse, resultando em 37 artigos utilizados como referência, dentre os quais 8 principais foram elucidados em um quadro, e outros 21 referenciados ao longo do texto (Figura 1).

Figura 1 - Metodologia utilizada e elegibilidade de artigos.
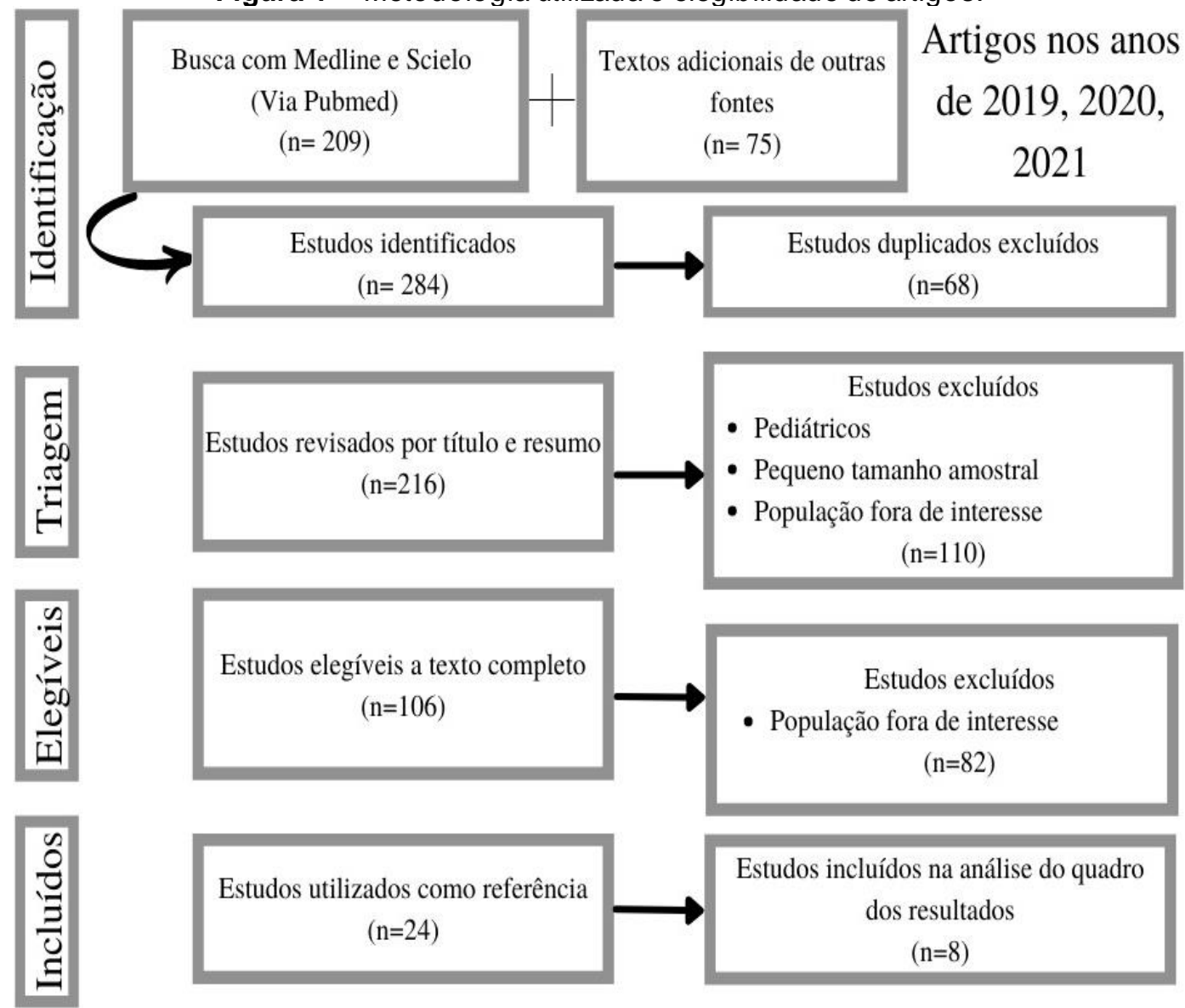

Fonte: Nascimento YS, et al., 2021.

\section{RESULTADOS E DISCUSSÃO}

O Quadro 1 sintetiza os objetivos dos artigos escolhidos e os principais dados encontrados a partir da revisão feita. 
Quadro 1 - Principais achados de alguns dos artigos selecionados.

\begin{tabular}{|c|c|c|}
\hline Artigo, ano & Proposta & Principais achados \\
\hline $\begin{array}{l}\text { Gralinski LE, et } \\
\text { al. (2018). }\end{array}$ & $\begin{array}{l}\text { Apresentar os principais achados das } \\
\text { pró-citocinas no processo inflamatório da } \\
\text { SARS-CoV-2. }\end{array}$ & $\begin{array}{l}\text { Os achados apontaram que as citocinas } \\
\text { inflamatórias IL-6, IL-17 e FNTA foram } \\
\text { elevados em pacientes com resultados } \\
\text { graves. }\end{array}$ \\
\hline $\begin{array}{l}\text { Ameratunga } S \text {, et } \\
\text { al. (2006). }\end{array}$ & $\begin{array}{l}\text { Apresentar os principais achados da } \\
\text { literatura científica sobre a coagulopatia } \\
\text { em pacientes com SARS-CoV- } 2 \text {. }\end{array}$ & $\begin{array}{l}\text { Os achados apontaram que a coagulopatia } \\
\text { se mostrou presente em } 50 \% \text { dos pacientes } \\
\text { que morreram contra } 7 \% \text { dos que } \\
\text { sobreviveram. }\end{array}$ \\
\hline $\begin{array}{c}\text { Guan W, et al. } \\
(2020) .\end{array}$ & $\begin{array}{l}\text { Apresentar os principais achados da } \\
\text { literatura cientifica sobre níveis de D- } \\
\text { dímero em pacientes positivos para } \\
\text { SARS-CoV-2. }\end{array}$ & $\begin{array}{l}\text { Os achados apontaram que o nível de D- } \\
\text { dímero estava acima de } 0,5 \mathrm{mg} / \mathrm{l} \text { em } 46,5 \% \\
\text { dos pacientes, onde } 60 \% \text { desenvolveram } \\
\text { uma manifestação severa. }\end{array}$ \\
\hline $\begin{array}{l}\text { Bompard F, et al. } \\
(2020) .\end{array}$ & $\begin{array}{l}\text { Apresentar os principais achados da } \\
\text { literatura cientifica sobre exames de } \\
\text { angiografia pulmonar realizados em dois } \\
\text { hospitais da Universidade de Paris. }\end{array}$ & $\begin{array}{l}\text { Os achados apontaram que } 18 \text { casos } \\
\text { envolviam artérias pulmonares e } 4 \text { estavam } \\
\text { envolvidos em múltiplos segmentos. }\end{array}$ \\
\hline $\begin{array}{l}\text { Fox SE, et al. } \\
\text { (2020). }\end{array}$ & $\begin{array}{l}\text { Apresentar os achados relacionados a } 4 \\
\text { autópsias de pacientes positivos para } \\
\text { SARS-CoV-2. }\end{array}$ & $\begin{array}{l}\text { Os achados demonstraram que não houve } \\
\text { tromboembolismo na maioria das artérias } \\
\text { pulmonares, entretanto pequenos trombos } \\
\text { estavam presentes em pequenos } \\
\text { segmentos no parênquima do pulmão. }\end{array}$ \\
\hline $\begin{array}{c}\text { García-lledó A, et } \\
\text { al. (2021). }\end{array}$ & $\begin{array}{l}\text { Apresentar os achados relacionados as } \\
\text { tomografias feitas em pacientes com } \\
\text { suspeita de TEP positivos para SARS- } \\
\text { CoV-2. }\end{array}$ & $\begin{array}{l}\text { Os achados demonstraram que no período } \\
\text { controle houve } 22 \text { eventos de } \\
\text { tromboembolismo, enquanto que na } \\
\text { pandemia esse índice subiu para } 99 \text { casos, } \\
\text { dos quais } 74 \text { foram associados a resultados } \\
\text { positivos para o teste RT-PCR para SARS- } \\
\text { CoV-2 }\end{array}$ \\
\hline $\begin{array}{c}\text { Chamorro EM, et } \\
\text { al. }(2021)\end{array}$ & $\begin{array}{l}\text { Apresentar os achados relacionados ao } \\
\text { software SPSS para analisar a } \\
\text { prevalência de embolia pulmonar em } \\
\text { pacientes positivos para SARS-CoV- } 2 \text {. }\end{array}$ & $\begin{array}{l}\text { Os achados demonstraram que } 61,7 \% \\
\text { apresentaram consolidações, descritas } \\
\text { como um achado fundamental na fase pico } \\
\text { da doença, de } 9 \text { a } 13 \text { dias após o início dos } \\
\text { sintomas }\end{array}$ \\
\hline $\begin{array}{c}\text { Marcos SZ, et al. } \\
(2021)\end{array}$ & $\begin{array}{l}\text { Apresentar os achados relacionados ao } \\
\text { internamento de pacientes com SARS- } \\
\text { CoV-2 e sua relação com o sistema ABO } \\
\text { para predisposição do TEP. }\end{array}$ & $\begin{array}{l}\text { Os achados demonstraram que os grupos } \\
\text { sanguíneos } A B \text { e } B \text { têm uma prevalência } \\
38 \% \text { maior no grupo infectado que na } \\
\text { população geral. O estudo sugere, também, } \\
\text { que indivíduos do tipo sanguíneo O tem } \\
\text { menor suscetibilidade à infecção e } \\
\text { complicações, especialmente aquelas de } \\
\text { origem trombogênica. }\end{array}$ \\
\hline
\end{tabular}

Fonte: Nascimento YS, et al., 2021.

Os achados de Gralinski LE, et al. (2018), em seu estudo demonstraram que as pró-citocinas inflamatórias interleucina 6 (IL-6), interleucina 17A (IL-17A) e fator de necrose tumoral alfa (FNTA) foram elevados na maioria dos pacientes com resultados graves. Foi evidenciado, em outro estudo, que cená rios de coagulopatia foram percebidos, baseados em estudos que documentam mudanças laboratoriais e clinicas de pacientes com SARS-CoV-2, em mais de $50 \%$ dos pacientes com manifestações graves. Mais adiante nesse mesmo estudo, é feita uma análise multivariada comparando os parâmetros laboratoriais e clínicos de 137 sobreviventes para 54 não-sobreviventes, a razão de possibilidades de mortalidade (OR) para aqueles com níveis de D-dímero $>0.5 \mathrm{mg} / \mathrm{ml}$ foi de 2,14 e para aqueles com níveis de $\mathrm{D}$-dímero $>1 \mathrm{mg} / \mathrm{ml}$ foi de 18,42 . Dessa forma, esse estudo mostrou que a coagulopatia ocorreu em $50 \%$ dos pacientes que morreram contra $7 \%$ de pacientes que sobreviveram, demonstrando a forte relação entre altos níveis de $D$-dímero em pacientes acometidos com a SARS-CoV-2 e alto índice de mortalidade (AMERATUNGA S, et al., 2006). 
Os achados do artigo de Guan W, et al. (2020), demonstram que, em um estudo incluindo 1099 pacientes positivos para a SARS-CoV-2 de 552 hospitais na China, os níveis de concentração de D-dímero estavam acima de $0.5 \mathrm{mg} / \mathrm{l}$ em $46,5 \%$ dos pacientes, onde $60 \%$ deles desenvolveram uma manifestação severa. Nesses pacientes, as concentrações de D-dímero de $2,12 \mathrm{mg} / \mathrm{ml}$ eram 4 vezes maiores quando comparados aos pacientes que não foram af etados severamente $(0,61 \mathrm{mg} / \mathrm{ml})$, concluindo que a concentração de $D$-dímero e o escore SOFA, somando-se com a idade do paciente, são uma informação importante para a prognose da infecção do novo coronavírus.

Os achados de um estudo retrospectivo que avaliou todos os exames de angiografia pulmonar computadorizada entre 1 março e 16 de abril de 2020, nos pacientes com SARS-CoV-2 e pneumonia em dois hospitais da Universidade de Paris evidenciaram que houve 10 embolismos pulmonares proximais e 22 periféricos, onde 18 desses casos envolveram artérias pulmonares e 4 estavam envolvidos em múltiplos segmentos das artérias pulmonares. Nesse estudo, o uso profilático de anticoagulantes não conseguiu evitar a ocorrência de embolismo pulmonar nos pacientes hospitalizados, ressaltando a necessidade de adaptar a profilaxia para trombose em pacientes infectados com SARS-CoV-2 (BOMPARD F et al., 2020).

Em 4 autópsias feitas em pacientes infectados por SARS-CoV-2, de New Orleans, com uma descompensação respiratória súbita, foi mostrado que não houve tromboembolis mo na maioria das artérias pulmonares, mas pequenos trombos estavam presentes em pequenos segmentos do parênquima pulmonar. Quando foi analisado posteriormente em um microscópio, foi confirmado que esses pequenos vasos continham pequenos trombos que estavam espalhados causando danos no tecido alveolar, tornando possível concluir que pequenos vasos podem ser af etados pelos microtrombos (FOX SE, et al., 2020).

Os resultados de García-Lledó A, et al. (2021), que analisou todas as tomografias solicitadas por suspeita de tromboembolismo pulmonar em um período de controle em 2019 e no mesmo período em 2020, durante a pandemia, foram de que no período controle houveram 22 eventos de tromboembolismo, enquanto que na pandemia esse índice subiu para 99 casos, dos quais 74 foram associados a resultados positivos para 0 teste RT-PCR para SARS-CoV-2. A análise do número de pacientes internados por SARS-CoV-2 no período durante a pandemia mostrou que $5,7 \%$ desses pacientes obtiveram o diagnóstico de TEP, além da relação entre o risco de TEP durante o período analisado no início da pandemia em relação ao período controle ter sido de 4,5. Esse estudo traz, ainda, que os pacientes diagnosticados com tromboembolismo pulmonar durante a pandemia possuíam menores taxas de condições predisponentes, como embolismo pulmonar prévio, cirurgia prévia e trombose de veias profundas (GARCíA-LLEDÓ A, et al., 2021).

É apresentado no estudo de Chamorro EM et al. (2021), que a prevalência de embolismo pulmonar em pacientes com SARS-CoV-2 é maior do que naqueles que ainda não se estabeleceu a doença (26\% vs. $16 \%)$, ajudando na confirmação de dados publicados em outros estudos. Foi utilizado o software SPSS nesse estudo, que é responsável por capturar e analisar dados para criar tabelas e gráficos com dados complexos. Todos os pacientes incluídos nesses estudos apresentaram níveis aumentados de D-dímero corrigidos de acordo com a idade, embora a diferença não tenha sido significativa, onde a mediana foi de $6083 \mu \mathrm{g} / \mathrm{mL}$ no grupo de pacientes com SARS-CoV-2 e $4491 \mu \mathrm{g} / \mathrm{mL}$ no grupo sem infecção com SARS-CoV-2. 94\% dos pacientes com SARS-CoV-2 e embolismo pulmonar tiveram envolvimento pulmonar na tomografia computadorizada de tórax, onde, de $32,6 \%$ apresentaram vidro fosco, $40,4 \%$ com consolidações e $21,3 \%$ consolidações e distorções da arquitetura pulmonar. Sendo assim, 61,7\% apresentaram consolidações, descritas como um achado fundamental na fase pico da doença, de 9 a 13 dias após o início dos sintomas (CHAMORRO EM, et al., 2021).

Já no estudo elaborado por Marcos SZ, et al. (2020), que analisou pacientes internados com SARS-CoV2, os grupos sanguíneos desses pacientes e também uma base populacional, foi demonstrado que indivíduos dos grupos sanguíneos AB e B têm uma prevalência 38\% maior no grupo infectado que na população geral, além de que o grupo $B$ apresentou maiores taxas de trombose $(26,8 \%)$ e de internação em Unidade de Tratamento Intensivo (38,1\%). O estudo também sugeriu que indivíduos do tipo sanguíneo $\mathrm{O}$ teriam menor suscetibilidade à infecção e complicações, especialmente aquelas de origem trombogênica. 
Assim como na SARS, existe uma ligação entre inflamação e lesões graves em órgãos de pacientes com SARS-CoV-2. A patologia primária é a síndrome respiratória aguda grave e é caracterizada por danos alveolares difusos incluindo membranas hialinas. As evidencias apontam para uma possível tempestade de citocinas decorrente do alto teor inflamatório da SARS-CoV-2. As citocinas pró-inflamatórias estão crucialmente envolvidas em formações de coágulos anormais e hiperativação plaquetária e assume papel importante na desregulação de importantes caminhos anticoagulatórios fisiológicos. Em outras palavras, a SARS-CoV-2 desencadeia um estado inflamatório em que, entre outros mecanismos, resulta na ativação da cascata de coagulação e situações de disfunção endotelial, que condiciona um risco aumentado para eventos tromboembólicos (GUZIK TJ, et al., 2020; LODIGIANI C, et al., 2020).

Essa cascata de coagulação é iniciada na tentativa de desintegrar um trombo, que pode futuramente se tornar um êmbolo, na corrente sanguínea. Entretanto, o verdadeiro problema surge quando essa cascata é incapaz de causar a fibrinólise, podendo formar um êmbolo que poderá viajar pela circulação até atingir o pulmão, causando dificuldades de perfusão e, possivelmente, o tromboembolismo pulmonar. $O$ vírus da SARS-CoV-2 provoca a Síndrome Respiratória Aguda Grave (SRAG). A SRAG é uma manifestação clínica da resposta do organismo a um dano pulmonar grave, causando o disparo de uma série de mecanismos fisiológicos de defesa e passando a existir uma forma de autoagressão, amplificando ainda mais a resposta inflamatória, que poderá influenciar ainda mais os fatores coagulativos para a geração de trombos (BRANDÃO SCS, et al., 2020).

O tromboembolismo pulmonar, que vem sendo apontado como uma das principais complicações da SARS-CoV-2, é caracterizado pelo alojamento de um trombo, que mais comumente tem por origem uma trombose venosa profunda, nas artérias pulmonares. A obstrução de fluxo nas artérias pulmonares sobrecarrega o ventrículo direito, podendo ocasionar um grave comprometimento hemodinâmico. Condições que levam a uma predisposição para tal fenômeno incluem doença pulmonar obstrutiva crônica (DPOC), cirurgias prévias, trauma, gravidez, além de predisposições genéticas (ESSIEN EO, et al., 2019).

Torna-se importante, então, analisar o perfil dos pacientes com SARS-CoV-2 que desenvolveram TEP. Existem diferenças no perfil dos pacientes que desenvolvem a condição devido à infecção por SARS-CoV-2 e pacientes que a desenvolvem sem a infecção, sendo os pacientes com SARS-CoV-2 portadores de menos condições predisponentes como histórico de embolia pulmonar prévia, trombose venosa profunda e cirurgias anteriores. Tais diferenças corroboram para o já comprovado estado hipercoagulativo da SARS-CoV-2 (GARCÍA-LLEDÓ A, et al., 2021).

$\mathrm{O}$ aumento de casos da SARS-CoV-2 e sua consequente globalização, trouxe à tona uma possível correlação entre o sistema ABO com a inf ecção do SARS-CoV-2 2, bem como a ocorrência de complicações de origem vascular, como o tromboembolismo pulmonar. Em ambas as situações, indivíduos do grupo sanguíneo $O$ demonstram menores chances de infecção, menor carga viral e menor incidência de complicações. Este fenômeno está ligado, primeiramente, a presença de antígenos anti-A e anti-B no soro de pacientes do grupo O (MARCOS SZ, et al., 2020).

A proteína Spike do envelope do SARS-CoV-22 possui vários sítios de glicosilação e, uma vez que a síntese de proteínas virais depende do maquinário celular do hospedeiro, pode-se concluir que virions produzidos em células do endotélio respiratório possuam na estrutura glicoproteica da proteína $S$ antígenos $\mathrm{A}, \mathrm{B}$ e $\mathrm{H}$, dependendo do fenótipo secretor individual. Indivíduos do grupo $\mathrm{O}$, que apresentem antígenos antiA e anti-B por sensibilização prévia possuiriam, portanto, maiores chances de não serem infectados ou possuírem uma carga viral menor. Em relação à incidência de complicações de origem trombótica, já é sabido que pessoas do grupo sanguíneo $O$ possuem concentrações plasmáticas cerca de $30 \%$ menores do fator de Von Willebrand, que possui importante papel na cascata da coagulação (PENDU JL, et al., 2021).

O SARS-CoV-2 2 penetra as células epiteliais alveolares através de um receptor de superfície da enzima conversora da angiotensina 2 (ACE2). A ACE2 ativa o sistema renina-angiotensina, que leva a uma regulação negativa da expressão de ACE2. Isso resulta em um aumento na angiotensina II e uma diminuição, por outro lado, da angiotensina1. Nesse sentido a SARS-CoV-2 infecta as células endoteliais que expressam a ACE2. 
Há uma ativação da cascata de coagulação, que gera trombina a partir de protrombina por ação do fator de coagulação $X$. As plaquetas circulantes ativadas se agreg am e proporcionam à superfície fosfolipídica uma adequação para a adesão dos diferentes compostos da cascata de coagulação, com geração de grande quantidade de trombina (ZHANG $\mathrm{H}$ et al., 2020).

ACE2 é expressa predominantemente no endotélio vascular das células do pulmão, mas também no tecido extrapulmonar, coração, sistema nervoso, intestino, rins, vasos sanguíneos e músculos, o que pode explicar a possível disfunção em múltiplos órgãos observados em pacientes com SARS-CoV-2. A angiotensina 2 é conhecida por ser um dos mais potentes vasoconstrictores e também aumenta a hipercoagulabilidade. A elevação de ACE2 vem sendo um importante marcador relatado em pacientes acometidos pela infecção (ZHANG H, et al., 2020).

O risco alto de trombose em SARS-CoV-2 é demonstrado pelo aumento em D-dímero, além de outros fatores como idade avançada e doenças prévias, que se mostrou a mudança mais significante entre os marcadores inflamatórios em pacientes acometidos pela inf ecção durante o agrupamento de estud os, sugere um aumento de trombina e produção e ativação da fibrinólise (TANG N, et al., 2020a).

Sabe-se que o D-dímero pode estar elevado por conta de outras causas que não a inflamação, entretanto foi mostrado que o aumento consecutivo de D-dímero pode indicar a presença de trombose e embolismo pulmonar em pacientes da SARS-CoV-2. Nos estudos, foi demonstrado que os níveis de D-dímero superiores a $1 \mathrm{mg} / \mathrm{ml}$ em pacientes com o novo coronavírus constituem um índice prognostico relevante de mortalidade. A resposta inflamatória sistêmica e o dano endotelial associados a infecção viral ativariam a coagulação com aumento da geração de trombina e diminuição dos anticoagulantes naturais do organismo, servindo como explicação para as possíveis hemorragias em casos de tempestades de citocinas (FRANCO-MORENO A, et al., 2020; ULLAH W, et al., 2020).

Outros marcadores inflamatórios também tem um aumento relevante em pacientes do novo coronavírus acometidos por TEP, dentre eles a proteína $C$ reativa, ferritina, procalcitonina e NT-proBNP (COSTA IBSS, et al, 2020). A proteína $C$ reativa (PCR) é um marcador inflamatório considerado forte preditor independente de risco para evento e morte cardiovascular. Sua síntese ocorre nos hepatócitos sob estímulo primário da IL-6. A ferritina, por sua vez, é uma proteína globular que se localiza essencialmente no fígado e é uma das mais importantes proteínas de reserva do ferro, sendo também uma proteína que apresenta considerável elevação no quadro de SARS-CoV-2. A procalcitonina é um pró-hormônio que em condições habituais permanece no interior das células $C$ da tireoide, sendo precursor da calcitonina, no entanto, foi verificado seu aumento nos pacientes infectados (JACINTO DM, et al., 2020; DENARDI CAS, et al., 2008; COSTA IBSS, et al., 2020).

O NT-proBNP, que é o fragmento N-terminal do peptídeo natriurético tipo $\mathrm{B}$, normalmente serve como um marcador de insuficiência cardíaca e é extremamente útil no prognóstico de diversas doenças, ganhando cada vez mais relevância nos estudos que envolvem a SARS-CoV-2, o coração e o tromboembolismo pulmonar. Jacinto DM, et al. (2020) citaram em seu estudo dosagens de 7942 pacientes que corroboram com a ideia do monitoramento desses marcadores, concluindo que eles são preocupantes quando elevados em pacientes da SARS-CoV-2, podendo até acarretar em diversos problemas vasculares, bem como a TEP (DENARDI CAS, et al., 2008; COSTA IBSS, et al., 2020).

As evidências de que a SARS-CoV-2 causa dano endotelial devido ao contato viral e à resposta inflamatória sistêmica, seguida de uma possível tempestade de citocinas, vêm crescendo cada vez mais. A tempestade de citocinas é um termo que designa um compilado de desordens imunitárias, caracterizada por inflamação sistêmica, e disfunção orgânica generalizada. Nesse sentido, trata-se de uma síndrome extremamente preocupante e de difícil tratamento, onde há a tentativa de identificaro motivo dessa desordem sistêmica, estabelecendo a severidade e determinando a trajetória clínica. A identificação de uma tempestade de citocinas, apesar de ser bastante comum nos pacientes com SARS-CoV-2, é bastante complexa (FAJGENBAUM DC e JUNE CH, 2020).

Fajgenbaum DC e June $\mathrm{CH}$, (2020), sugerem ainda que os critérios para identificar uma tempestade de citocinas são: Níveis de citocinas elevadas na circulação, sintomas de inflamação sistêmica aguda e tanto 
disfunção orgânica secundária ou uma disfunção orgânica pelas citocinas. O dano endotelial, nesse sentido, pode se manif estar tanto como uma doença tromboembólica, como tromboembolismo pulmonar, tornando-se necessária a criação de estratégias para o tratamento de tromboembolismo pulmonar para pacientes da SARS-CoV-2. A fisiopatologia que relaciona o TEP com a infecção da SARS-CoV-2 ainda não é completamente conhecida, entretanto parece estar relacionada com um estado de hipercoagulabilidade (TANG N, et al., 2020b; FRANCO-MORENO A, et al., 2020).

A Figura 2 apresenta, com base nos artigos revisados, alguns fatores indicativos de má prognóstico na evolução da SARS-CoV-2 e seu possível desenvolvimento para TEP.

Figura 2 - Fatores indicativos de má prognóstico na evolução da SARS-CoV-2 e provável desenvolvimento Tromboembolismo Pulmonar.

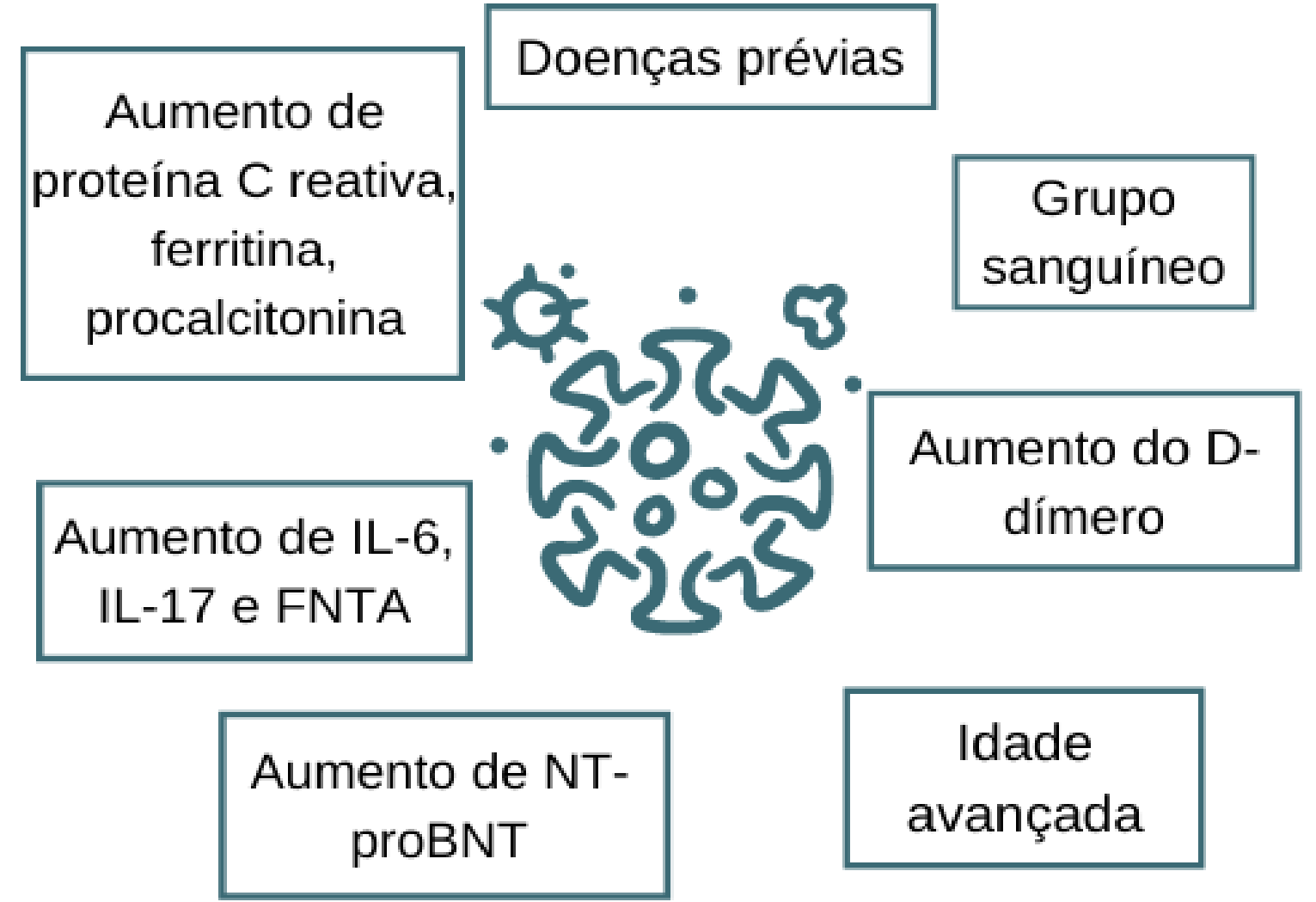

Legenda: IL=Interleucina; FNTA = Fator de necrose tumoral alfa; NT-proBNT = N-terminal própeptídeo natriurético tipo-B. Fonte: Nascimento YS, et al., 2021. Fundamentado em: FrancoMoreno A, et al., 2020; Tang N, et al., 2020a; Tang N, et al., 2020b; Ullah W, et al., 2020.

\section{CONSIDERAÇÕES FINAIS}

Nesses estudos observou-se que a insuficiência respiratória grave que ocorre nos pacientes com SARSCoV-2 não é o único problema grave que pode ocorrer. A prevalência de ACE2, enzima essa que é desregulada pelo vírus da SARS-CoV-2, em diversos órgãos é um fator que se torna perceptível nos locais com maiores danos teciduais. A desregulação da ACE2 pode acabar por gerar desregulação de eventos de coagulação e originar situação de tromboembolismo. As coagulopatias presentes no s pacientes deixam clara a necessidade de se implantar diferentes estratégias antitrombóticas, especialmente nos pacientes graves que entraram em unidade de tratamento intensivo. É importante ter um monitoramento dos fatores de coagulação e marcadores inflamatórios, tais como, níveis de D-dímero, proteína C reativa, ferritina e NTproBNP, bom como estar alerta ao grupo sanguíneo, buscando um manejo correto com rápida identificação e implementação do tratamento adequado. Dessa maneira, essa revisão de literatura serve de contribuição ao entendimento mais aprofundados das possíveis correlações entre o TEP o SARS-CoV-2. 


\section{REFERÊNCIAS}

1. AMERATUNGA S, et al. Road-traffic injuries: confronting disparities to address a global-health problem. The Lancet, 2006;367(9521): 1533-1540.

2. BOMPARD F, et al. Pulmonary embolism in patients with SARS-CoV-2 pneumonia. European Respiratory Journal, 2020;56(1).

3. BRANDÃO SCS, et al. SARS-COV-2, Imunidade, Endotélio e Coagulação: Compreenda a Interação. 2020.

4. CHAMORRO EM, et al. Tromboembolismo pulmonar en pacientes con SARS-COV-2: estudio de prevalencia en un hospital terciario. Radiología, 2021; 63(1):13-21.

5. COSTA IBSS, et al. O Coração e a SARS-COV-2: O que o Cardiologista Precisa Saber. Arquivos Brasileiros de Cardiologia, 2020;114(5):805-816.

6. DENARDI CAS, et al. A proteina C-reativa na atualidade. Rev Socerj, 2008;21(5):329-34.

7. ESSIEN EO, et al. Pulmonary Embolism. The Medical Clinics of North America, 2019;103(3):549-564.

8. FAJGENBAUM DC, JUNE CH. Cytokine storm. New England Journal of Medicine, 2020;383(23):2255-2273.

9. FOX SE, et al. Pulmonary and cardiac pathology in African American patients with SARS-COV-2: an autopsy series from New Orleans. The Lancet Respiratory Medicine, 2020;8(7): 681-686.

10. FRANCO-MORENO A, et al. Tromboembolismo pulmonar y SARS-COV-2: un cambio de paradigma. Revista clínica española, 2020;220(7):459-61.

11. GARCÍA-LLEDÓ A, et al. Tromboembolismo pulmonar durante la pandemia por SARS-CoV-2: características clínicas y radiológicas. Revista Clinica Espanola, 2021.

12. GRALINSKI LE, et al. Complement activation contributes to severe acute respiratory syndrome coronavirus pathogenesis. MBio, 2018; 9(5).

13. GUAN W, et al. Clinical characteristics of coronavirus disease 2019 in China. New England journal of me dicine, 2020; 382(18): 1708-1720.

14. GUZIK TJ, et al. SARS-COV-2 and the cardiovascular system: implications for risk assessment, diagnosis, and treatment options. Cardiovascular research, 2020;116(10):1666-1687.

15. JACINTO DM, et al. Descrição das alterações do hemograma correlacionados à Proteína C Reativa (PCR) e ferritina em 7942 pacientes com Sars-CoV-2. Hematology, Transfusion and Cell Therapy, 2020;42:529.

16. LIMA FLO, et al. Diagnóstico da SARS-COV-2: importância dos testes laboratoriais e dos exames de imagem. Research, Society and Development, 2020;9(9):e259997162-e259997162.

17. LODIGIANI C, et al. Venous and arterial thromboembolic complications in SARS-COV-2 patients admitted to an academic hospital in Milan, Italy. Thrombosis research, 2020;191:9-14.

18. MARCOS SZ, et al. Infección y trombosis asociada a la SARS-COV-2: posible papel del grupo sanguíneo ABO. Medicina Clínica, 2020;155(8): 340-343.

19. MIESBACH W, MAKRIS M. SARS-COV-2: coagulopathy, risk of thrombosis, and the rationale for anticoagulation. Clinical and Applied Thrombosis/Hemostasis, 2020;26:1076029620938149.

20. PENDU JL, et al. ABO Blood Types and SARS-COV-2: Spurious, Anecdotal, or Truly Important Relationships? A Reasoned Review of Available Data. Viruses, 2021;13(2): 160.

21. TANG N, et al. Abnormal coagulation parameters are associated with poor prognosis in patients with novel coronavirus pneumonia. Journal of thrombosis and haemostasis, 2020a;18(4):844-847.

22. TANG N, et al. Anticoagulant treatment is associated with decreased mortality in severe coronavirus disease 2019 patients with coagulopathy. Journal of thrombosis and haemostasis, 2020b; 18(5): 1094-1099.

23. ULLAH W, et al. Sars-CoV-2 complicated by acute pulmonary embolism and right-sided heart failure. Case Reports, 2020;2(9): 1379-1382.

24. ZHANG H, et al. Angiotensin-converting enzyme 2 (ACE2) as a SARS-CoV-2 receptor: molecular mechanisms and potential therapeutic target. Intensive care medicine, 2020;46(4):586-590. 